NBER WORKING PAPER SERIES

\title{
WHO IS IN CONTROL? THE DETERMINANTS OF PATIENT ADHERENCE WITH MEDICATION THERAPY
}

\author{
Sergei Koulayev \\ Niels Skipper \\ Emilia Simeonova \\ Working Paper 19496 \\ http://www.nber.org/papers/w19496
}

\author{
NATIONAL BUREAU OF ECONOMIC RESEARCH \\ 1050 Massachusetts Avenue \\ Cambridge, MA 02138 \\ October 2013
}

The authors would like to thank the Danish Council for Independent Research for financial support (grant no. 10-093296) The views expressed herein are those of the authors and do not necessarily reflect the views of the National Bureau of Economic Research.

NBER working papers are circulated for discussion and comment purposes. They have not been peerreviewed or been subject to the review by the NBER Board of Directors that accompanies official NBER publications.

(C) 2013 by Sergei Koulayev, Niels Skipper, and Emilia Simeonova. All rights reserved. Short sections of text, not to exceed two paragraphs, may be quoted without explicit permission provided that full credit, including $\odot$ notice, is given to the source. 
Who Is in Control? The Determinants of Patient Adherence with Medication Therapy Sergei Koulayev, Niels Skipper, and Emilia Simeonova

NBER Working Paper No. 19496

October 2013

JEL No. I1,I12

\section{$\underline{\text { ABSTRACT }}$}

Non-compliance with medication therapy remains an unsolved and expensive problem for health care systems around the world. Yet we know little about the factors that determine a patient's decision to follow treatment recommendations. This study uses a unique panel dataset comprising all prescription drug users, physicians, and all prescription drug sales in Denmark over seven years to analyze the contributions of doctor-, patient-, and drug-specific factors to the adherence decision. Our findings have important implications for the design of incentive schemes targeted at improving chronic disease management.

Sergei Koulayev

Keystone Strategy

Cambridge MA

sergei.koulayev@gmail.com

Niels Skipper

Department of Economics and Business

Aarhus University

Fuglesangs Allé 4

DK 8210 Aarhus V

Denmark

nskipper@econ.au.dk
Emilia Simeonova

JHU Carey School of Business

100 International Drive

Baltimore, MD 21202

and NBER

emilia.simeonova@gmail.com 


\section{Introduction}

Individual health behavior plays a vital role in determining the long-term health of the population. Advances in medical technology and treatment breakthroughs cannot be fully realized if patients do not adhere with the prescribed pharmaceutical therapy or implement the recommended changes in lifestyle that accompany it. The important role of patient medication non-adherence as a contributor to preventable morbidity and mortality has been demonstrated in numerous studies and across many conditions (see review by Krueger et al, 2005). Non-adherent patients with heart failure are more than twice as likely to have been admitted to a hospital and to die from heart failure (Miura et al, 2005). Similarly striking differences in health outcomes have been reported across adherence levels with beta blockers, asthma medication, and anti-psychotics (Kruger et al, 2005). Non-adherence imposes significant monetary costs on the health care system ${ }^{1}$. Studies have found that between one- and two-thirds of medication-related hospital admissions in the United States are due to poor medication adherence, with a cost of around $\$ 100$ billion per year (Osterberg and Blasche, 2005).

Past research has identified a range of factors that may affect the patient's decision to follow the prescribed medication regimen. These factors include but are not limited to: side effects, regimen complexity, limited patient attention and cognition, ineffective provider-patient communication, confusion about treatment instructions, misperception of the treatment's necessity, lack of social support, and financial burden (see review by Osterberg \& Blasche, 2005). An important question for policy is whether non-compliance can be addressed with appropriately designed incentives.

A review of the literature concludes that the existing evidence on the effects of patient- and provider-centered incentive schemes on adherence is mixed (Health Affairs, 2012; Volpp and Pauly 2009). One reason for the mixed performance of incentive schemes is the lack of understanding of the nature of the process that generates the medication adherence process. Indeed, an authoritative recent review by RAND argues that there is little evidence on the relative contributions of factors that affect patient adherence (Gallad et al, 2009). In particular, we do not know whether, or in what situations, physicians are able to affect patient decisions to invest in their health. Moreover, it is not

\footnotetext{
${ }^{1}$ As a large contributor to health care costs, the problem of non-adherence has received significant attention in the recent debate surrounding health care reform. Articles in popular media have presented anecdotal evidence and proposed solutions to the problem. In discussing health care reform for the New York Times, Sandeep Jauhar wrote that "Patient noncompliance with medical recommendations undoubtedly contributes to poor health, but it is as much a function of poor communication, medication costs and side effects, cultural barriers and inadequate resources as it is of willful disregard of a doctor’s advice.”
} 
clear how different might be the patient response to physician effort and whether the ultimate success of medication therapy can be entrusted solely to either one of these two agents.

This research contributes to the literature in several ways. First, we analyze the determinants of patient adherence with prescribed therapy using administrative data from Denmark, comprising the complete medication histories of the entire adult Danish population during the period 2004-2010. The record of medical encounters is matched to the registry of Danish primary care physicians. As a result, we are able to trace outpatient health care utilization and the formation of doctor-patient matches during the period. The panel nature of the data allows us to analyze the sources of both across- and within-patient variation in medication compliance. The universal nature of health insurance provided by the Danish government presents a rare opportunity to study population level determinants of adherence in a context not affected by financial barriers to health care.

Second, we study the relative contribution of provider- and patient-level factors to compliance with therapy prescriptions. Our results show that physicians exert substantive influence on patients' health behavior. However, we also find that a sizeable component of the variation in compliance cannot be explained by time-invariant patient or doctor characteristics, suggesting that the quality of the match between doctor and patient plays a role in compliance. Further analysis reveals that the match quality induces substantial variation in adherence over time within a physician-patient pair. In other words, adherence to the assigned therapy is in large part specific to a doctor-patient match and evolves together with the doctor-patient relationship.

Third, we estimate the effects of medication cost on the adherence decision, contributing to the large literature on price elasticity of demand for prescription drugs. We find that patients do respond to higher drug prices by reducing day to day adherence rates, but the effects of medication price are small relative to other factors.

\section{Background}

There are very few empirical studies on the role of physicians in fostering health-promoting patient adherence behavior (reviews by Kruger et al, 2005 and RAND, 2009). We are not aware of any large-scale, nationally representative research that evaluates the relative contribution of physicianlevel factors to patient medication adherence. Still, some theoretical work on the issue exists. The 
idea of rational non-adherence has been previously formalized as a "health belief model"2. The model predicts that patients are more likely to comply with doctors' orders when they feel susceptibility to illness, believe that the illness will have serious consequences for their well-being, and do not anticipate side effects. Johnston-Roberts and Mann (2003) examine patients' diaries to find intentional skipping of medications to avoid side effects, despite awareness of the health risks associated with such behavior. At the extreme, non-compliance can manifest as dropping out of treatment (non-persistence) or changing the doctor altogether ${ }^{3}$.

There are only a few empirical studies that use panel data on large populations of patients to examine non-cost-related factors that affect patient adherence. Work by Lamiraud and Geoffard (2007), Neslin, Rhoades and Wolfson (2009), Simeonova (2012, 2012) aim at discerning patient characteristics (age, gender, race, type and severity of the disease) and drug characteristics (financial cost, length and complexity of the regimen, side effects) that help explain the observed variation in compliance across patients. A major reason for the dearth of such studies is the lack of large-scale, individual level data, combined with information on physicians, visits and therapy prescriptions. This study analyzes the determinants of patient medication compliance in a unified framework that includes doctor-, patient-, and drug-specific information in a population-level panel dataset.

\section{Institutional Setting}

This subsection discusses some salient features of the Danish insurance, pharmacy, and health care systems. Denmark has universal and tax financed health insurance run by the government. All individuals residing in Denmark are automatically equipped with a social security number and a health card. The health card ensures free access and treatment at general practitioners, specialists, as well as free in-hospital stays. All services provided to an individual are then registered via the social security number and all expenses are picked up by the national health insurance.

\section{$\underline{\text { General practitioners }}$}

The Danish public health insurance provides visits and services at the general practitioner (GP) free of charge. In Denmark, GPs serve as gate-keepers to the rest of the health care system. Referrals to

\footnotetext{
${ }^{2}$ See e.g. Becker (1976), Becker and Maiman (1975), Rosenstock (1974), Conrad (1985) and more recently, Ellickson et al. (1999)

${ }^{3}$ As dicussed in Philipson and Hedges (1998), Chan and Hamilton (2006), Neslin, Rhoades and Wolfson (2009)
} 
specialists and hospital admissions go through the general practitioner. All individuals have a choice of GP, as long as the GP practice is located within 15km from the patient's home. Changing to a different GP costs a fee of $150 \mathrm{DKK}^{4}$, and can be done only if the new doctor is open for patient intake.

There are approximately 3,500 general practitioners in Denmark. From these, 2,200 are organized in single-practices. In order to get reimbursed by the national insurance, the physician needs to acquire a clinic-ID (ydernummer). The number of clinic licenses is controlled by the government, based on factors such as the population density in different areas. A clinic can deny to list new patients when they reach enrollments of over 1,600 patients per doctor in the clinic. After reaching more than 2,700 listed patients per doctor, the clinic needs to make a special application to the government to add more patients.

The GPs are responsible for a large portion of the patient's medication therapy. The GP has no financial incentives to choose specific medication brands. First-choice medication recommendations are issued by the national health authorities, but practitioners can choose a different therapy if they consider it more appropriate. Prescription drugs are sold at government licensed pharmacies only. All information about purchases is registered in a database at the Danish Medicines Agency (DMA).

\section{Pharmaceutical prices}

Prescription drugs are partially covered by the national insurance. The extent of coverage depends on the accumulated drug expenditures during the subsidy year (which does not correspond to the calendar year). The actual scheme may vary by year. For instance, in 2004 the expenditures in the interval $520-1,260 \mathrm{DKK}$ had coinsurance of 50\%, in the interval 1,260 - 2,950DKK it was $25 \%$, and above 2,950 DKK it was $15 \%$. Accumulated expenditures are based on a subsidy price, which is the price of the cheapest alternative of a specific drug.

The price setting for prescription drugs operates in a two-week cycle. Every 14 days, pharmaceutical companies report their wholesale prices to DMA, who then sets retail and subsidy prices in its pharmacies nationwide. If a drug is still under patent protection, the retail and subsidy price will be identical. If generic substitutes are available, the entire market is auctioned off to the

\footnotetext{
${ }^{4}$ USD \$1 is approximately DKK 5.6.
} 
lowest-price bidder, who will procure the necessary drugs to Danish pharmacies during the next two weeks. The auction price will become the official subsidy price, on which the coinsurance schemes are based. If a patient prefers a branded (more expensive) version of a drug, he or she will have to pay the difference out of pocket ${ }^{5}$. For further information on the institutional background of the Danish subsidy scheme for prescription drugs, see Simonsen et al (2013).

For all drugs considered in this study, generic alternatives were available during the study period; therefore, the government auction was the relevant price setting mechanism.

\section{Data and descriptive evidence}

We focus the analysis of patient adherence with four drug groups - ace inhibitors, beta blockers, statins, and oral anti-diabetics (hypoglycemics). All of these medications are intended for chronic use and have frequently been the subject of medication adherence studies (RAND, 2009). Patients whose medication regimen includes one of these drug groups are expected to continue this regimen for the rest of their lives. Ace inhibitors and beta blockers are used in the treatment of hypertension and heart disease; oral anti-diabetics are the first line of defense against early-stage diabetes mellitus; and statins are prescribed to lower cholesterol levels and to prevent acute cardio-vascular episodes such as heart attacks or strokes. The analysis dataset covers the period 2004-2010 and includes all adults in Denmark who received at least two prescriptions within a 6-month period for one of these drug groups ${ }^{6}$.

\subsection{Definition of patient adherence with medication therapy}

Any discussion of patient adherence with therapy must first spell out what is meant by a "therapy". While many notions are possible, in this study we take a narrow view of a therapy as continuous and regular intake of medications from a given drug group by the patient. As a further refinement, our notion of therapy is doctor-specific: it includes only prescriptions from a given doctor, and does not include prescriptions from other doctors whom the patient might have seen in the meantime ${ }^{7}$.

\footnotetext{
${ }^{5}$ Example: A consumer has accumulated expenditures ensuring a $50 \%$ coinsurance from the government and is about to buy Medication A. The lowest price of Medication A placed by a pharmaceutical company is DKK 50 and the second lowest price is DKK 100. If the consumer chooses to buy the product that cost DKK 100, she will have to pay the price difference between the two out of pocket.

${ }^{6}$ This restriction was imposed to avoid cases of misdiagnosis, erroneous prescriptions, or one-time treatments with particular chemical agents that are not intended to treat chronic conditions.

${ }^{7}$ Receiving a prescription form more than one physician at the same time happens very rarely, as we show below. This is determined by the institutional setting.
} 
This approach is consistent with the goal of our study, which is to examine determinants of adherence within the context of the doctor-patient relationship.

Reviews of the related literature often deplore the diversity in medication adherence measures used by researchers, which limits the comparability of results across different studies. Such heterogeneity is explained by data availability - studies that report the results from interventions to improve adherence usually monitor it more closely and accurately than do studies based on claims data. In this study we also use electronic pharmacy records to measure adherence, but do so with high accuracy thanks to the panel nature of the dataset and the ability to monitor all prescription medication pickups in the Danish pharmacy system.

Patient adherence is calculated on the level of individual refill as the portion of days between the current and the next refill during which the patient had access to medication (the "covered period"). As such, it is a continuous measure, ranging between $0 \%$ and $100 \%$. This adherence measure is often called the medication possession ratio (MPR) in the literature. Defining compliance on the refill level allows us to analyze changes in adherence during the course of the doctor-patient relationship.

The covered period is calculated by taking the stock of drugs available to the patient and dividing it by the daily dosage. The supply of medication available to the patient consists of two parts. First, there could be leftover drugs from previous refills. Second, there is a stock of drugs obtained at the latest trip to pharmacy. For example, if a patient had 1 week of medication supply left from a previous refill, and received 2 weeks' worth of medication on the current trip to the pharmacy, we will consider this refill to be 100\% adherent if the next observed refill happens within 3 weeks. However, if the same patient did not have any leftover stock, she would be assigned only $66 \%$ adherence rate for the current refill (only 2/3 of the period of three weeks between current and next refill is covered).

An important consideration in the calculation of adherence rates is how to treat refills obtained through prescriptions from other doctors who the patient has seen between visits to the main prescriber. We consider the doctor from whom the patient received the largest number of prescriptions during the year for the given condition as the main prescriber. As a general rule, we treat cases when the patient received only one or two refills for the same ATC-5 code from another doctor as visits to a "replacement doctor" and assign the adherence with these refills to the main 
doctor. For example, if we see a sequence of prescriptions from doctors A and B as follows: AAA...ABBAA...A, then we assign the two refills obtained from doctor $B$ to the therapy prescribed by doctor A. We do not calculate a separate patient adherence value with doctor B. But, if the sequence of refills includes 3 or more refills prescribed by doctor $B$, as in AAA...ABBBAA...A, even if they are followed by a another sequence of refills from doctor A, we consider doctor B as a contributing physician and calculate a separate doctor-specific adherence for refills prescribed by her. Note that cases of the type described above are very rare in the data. If a patient has seen more than one physician, there is usually a clear break from the first doctor visited, after which she visits only the second doctor and does not go back.

\subsection{Summary statistics of adherence rates}

Table 1 shows that mean adherence rates in this study are quite high, around 90\%. In Panel (1) we use the default adherence measure in the study, taking into account any leftover stock of medication from previous refills. In Panel (B) we calculate adherence rates that disregard any leftover medication supply. Ace inhibitors have the highest compliance levels, followed closely by statins and oral hypoglycemics, while beta blockers exhibit the lowest adherence rates. Within a drug group, the variation in adherence rates is substantial: the standard deviation is $1 / 5$ of the mean. This ensures that we will be able to identify factors that determine relative differences in adherence rates across patients and disease types.

Table 1. Summary statistics of adherence by drug group

\begin{tabular}{lccccc}
\hline Drug group & Mean & Median & SD & Fully adherent refills & N obs. \\
\hline (A) Default adherence measure: Taking into account leftover stock & from previous refills & & \\
ACE & 93.46 & 100.00 & 16.70 & $71 \%$ & $5,504,150$ \\
Beta blockers & 89.33 & 100.00 & 21.12 & $63 \%$ & 602,487 \\
Oral Antidiabetics & 90.88 & 100.00 & 19.14 & $66 \%$ & $2,570,297$ \\
Statins & 91.85 & 100.00 & 17.38 & $62 \%$ & $7,239,143$ \\
\multicolumn{7}{l}{ (B) Alternative adherence } & & & & \\
ACE & 89.38 & 100.0 & & $49 \%$ & $5,504,150$ \\
Beta blockers & 85.56 & 98.0 & 18.92 & $45 \%$ & 602,487 \\
Oral Antidiabetics & 86.27 & 99.5 & 22.21 & $47 \%$ & $2,570,297$ \\
Statins & 88.20 & 98.0 & 21.10 & $43 \%$ & $7,239,143$ \\
\hline
\end{tabular}


An alternative measure of adherence is the indicator measure of "on time" refills, where a refill is considered 100\% adherent (fully adherent) if picked up before the expiration of the previous refill's days' supply and 0\% adherent if the patient failed to pick up during the covered period. For all drug groups, between $60 \%$ and $70 \%$ of all refills are fully adherent with this definition. Although such adherence measure is intuitive and is often used, Table 1 suggests that this measure is too sensitive to the way "covered period" is calculated - including or excluding potentially leftover stock from previous refills.

In Panel (A), the adherence measure includes leftover stock of pills from previous refills. Such inclusion utilizes all available information and improves the adherence measure, for example, by distinguishing between patients with easier access to medication (drugs available at home) and patients who would need to make another trip to the pharmacy in order to stay compliant. Naturally, such approach results in higher average adherence levels: mean adherence rates in Panel (B), where leftover stock in not included, are 3-4pp lower. The effect of this change in methodology on the share of fully adherent refills is much more dramatic: this measure of adherence decreases by as much as 20pp once the information on leftover stock is removed ${ }^{8}$.

In Table 2 we examine differences in average compliance rates by patient demographic characteristics. Men are less compliant than women, and married people do better on average than singles. However, these differences are small compared to the effects of age and birth origin. The age gradient is quite steep: for ace inhibitors, every 10 years of age are associated with an increase in adherence rate of 2-3pp, particularly at the younger age groups. A difference of similar magnitude exists between patients who were born in Denmark and the foreign born. Even larger differences are obtained if we compare patients born in predominantly Muslim countries ${ }^{9}$ with the rest of the world: for beta blockers, the differential reaches 10 percentage points. Given that Danish healthcare system provides care free of charge for all patients, such difference in outcomes is surprising and requires further investigation.

\footnotetext{
8 This result partially explains the difference to US-based studies (RAND, 2009), which report adherence rates between $20 \%$ and $80 \%$.

${ }^{9}$ Needless say, Danish healthcare system does not differentiate patients by their religius affiliation. Therefore, our distinction between Muslim and non-Muslim-born patients is only an imperfect proxy for the actual religius affiliation.
} 
Table 2. Average adherence by demographic characteristics of a patient

\begin{tabular}{|c|c|c|c|c|}
\hline & Ace inhibitors & Beta Blockers & Oral Anti-diabetics & Statins \\
\hline \multicolumn{5}{|l|}{ Gender } \\
\hline Female & $\begin{array}{l}93.95 \\
(0.01)\end{array}$ & $\begin{array}{l}89.36 \\
(0.03)\end{array}$ & $\begin{array}{l}91.26 \\
(0.02)\end{array}$ & $\begin{array}{l}92.25 \\
(0.01)\end{array}$ \\
\hline Male & $\begin{array}{l}93.00 \\
(0.01)\end{array}$ & $\begin{array}{l}89.30 \\
(0.04)\end{array}$ & $\begin{array}{l}90.56 \\
(0.02)\end{array}$ & $\begin{array}{r}91.46 \\
(0.01)\end{array}$ \\
\hline \multicolumn{5}{|l|}{ Age } \\
\hline$<30$ & $\begin{array}{l}85.49 \\
(0.22)\end{array}$ & $\begin{array}{c}78.80 \\
(0.37)\end{array}$ & $\begin{array}{l}77.86 \\
(0.25)\end{array}$ & $\begin{array}{l}82.37 \\
(0.27)\end{array}$ \\
\hline 30 to 40 & $\begin{array}{l}87.89 \\
(0.08)\end{array}$ & $\begin{array}{l}81.90 \\
(0.19)\end{array}$ & $\begin{array}{l}82.72 \\
(0.10)\end{array}$ & $\begin{array}{c}85.16 \\
(0.09)\end{array}$ \\
\hline 40 to 50 & $\begin{array}{l}90.25 \\
(0.03)\end{array}$ & $\begin{array}{l}84.58 \\
(0.10)\end{array}$ & $\begin{array}{l}86.83 \\
(0.05)\end{array}$ & $\begin{array}{c}87.64 \\
(0.03)\end{array}$ \\
\hline 50 to 60 & $\begin{array}{l}92.10 \\
(0.02)\end{array}$ & $\begin{array}{l}87.35 \\
(0.07)\end{array}$ & $\begin{array}{l}89.52 \\
(0.03)\end{array}$ & $\begin{array}{c}90.17 \\
(0.02)\end{array}$ \\
\hline 60 to 70 & $\begin{array}{l}93.51 \\
(0.01)\end{array}$ & $\begin{array}{l}89.89 \\
(0.05)\end{array}$ & $\begin{array}{l}91.66 \\
(0.02)\end{array}$ & $\begin{array}{c}91.89 \\
(0.01)\end{array}$ \\
\hline $70+$ & $\begin{array}{l}94.66 \\
(0.01)\end{array}$ & $\begin{array}{l}91.80 \\
(0.04)\end{array}$ & $\begin{array}{l}92.78 \\
(0.02)\end{array}$ & $\begin{array}{l}93.36 \\
(0.01)\end{array}$ \\
\hline \multicolumn{5}{|l|}{ Marital status } \\
\hline Married & $\begin{array}{l}93.91 \\
(0.01)\end{array}$ & $\begin{array}{l}90.15 \\
(0.04)\end{array}$ & $\begin{array}{l}91.21 \\
(0.02)\end{array}$ & $\begin{array}{l}92.58 \\
(0.01)\end{array}$ \\
\hline Single & $\begin{array}{l}93.13 \\
(0.01)\end{array}$ & $\begin{array}{l}88.70 \\
(0.04)\end{array}$ & $\begin{array}{l}90.67 \\
(0.02)\end{array}$ & $\begin{array}{l}91.45 \\
(0.01)\end{array}$ \\
\hline \multicolumn{5}{|l|}{ Birth origin } \\
\hline Foreign & $\begin{array}{l}90.78 \\
(0.04)\end{array}$ & $\begin{array}{l}84.96 \\
(0.17)\end{array}$ & $\begin{array}{l}86.47 \\
(0.05)\end{array}$ & $\begin{array}{l}89.60 \\
(0.03)\end{array}$ \\
\hline Native & $\begin{array}{l}93.58 \\
(0.01)\end{array}$ & $\begin{array}{l}89.49 \\
(0.03)\end{array}$ & $\begin{array}{l}91.32 \\
(0.01)\end{array}$ & $\begin{array}{l}91.97 \\
(0.01)\end{array}$ \\
\hline \multicolumn{5}{|l|}{ Birth origin } \\
\hline Non-Muslim countries & $\begin{array}{l}93.52 \\
(0.01)\end{array}$ & $\begin{array}{l}89.44 \\
(0.03)\end{array}$ & $\begin{array}{l}91.18 \\
(0.01)\end{array}$ & $\begin{array}{c}91.92 \\
(0.01)\end{array}$ \\
\hline Predominantly Muslim countries & $\begin{array}{l}89.41 \\
(0.07)\end{array}$ & $\begin{array}{l}79.96 \\
(0.36)\end{array}$ & $\begin{array}{l}85.30 \\
(0.07)\end{array}$ & $\begin{array}{l}88.76 \\
(0.06)\end{array}$ \\
\hline
\end{tabular}

Note: standard errors in brackets under the means

Table 3 presents differences in average adherence by socio-economic status. These differences are much smaller than differences by age or birth origin. The correlation with income appears to be negative, as patients at high levels of income exhibit worse average adherence than poorer individuals. Differences across education levels are larger than those across income quartiles, but we find no clear patterns. Lower educational level does not necessarily lead to lower adherence, as demonstrated by adherence rates among individuals who did not graduate from high school. Because in Denmark income and education have little effect on access to health care, the observed differences may be due to unobserved behavioral traits, or simply due to selection. For instance, 
higher educated patients may seek doctors that give them more autonomy, or doctors with less "paternalistic" style.

Table 3. Average adherence by socio-economic characteristics of a patient

\begin{tabular}{lllll}
\hline & Ace inhibitors & Beta Blockers & $\begin{array}{l}\text { Oral Anti- } \\
\text { diabetics }\end{array}$ & Statins \\
\hline Income quintile & & & & \\
First & 93.71 & 90.35 & 91.10 & 92.29 \\
& $(0.01)$ & $(0.05)$ & $(0.02)$ & $(0.01)$ \\
Second & 94.53 & 91.00 & 91.86 & 93.20 \\
& $(0.01)$ & $(0.05)$ & $(0.02)$ & $(0.01)$ \\
Third & 93.32 & 88.72 & 90.88 & 91.82 \\
& $(0.01)$ & $(0.05)$ & $(0.02)$ & $(0.01)$ \\
Fourth & 92.26 & 86.85 & 89.64 & 90.26 \\
& $(0.01)$ & $(0.06)$ & $(0.03)$ & $(0.01)$ \\
Education & & & \\
Less than high school & 93.94 & 90.35 & 91.48 & 92.54 \\
& $(0.01)$ & $(0.04)$ & $(0.02)$ & $(0.01)$ \\
High School & 91.35 & 85.76 & 87.12 & 89.80 \\
& $(0.06)$ & $(0.22)$ & $(0.10)$ & $(0.06)$ \\
Vocational & 93.02 & 88.43 & 90.62 & 91.36 \\
Tertiary short term & $(0.01)$ & $(0.05)$ & $(0.02)$ & $(0.01)$ \\
& 92.37 & 87.43 & 89.98 & 90.64 \\
Tertiary medium term & $(0.05)$ & $(0.20)$ & $(0.08)$ & $(0.04)$ \\
Academic & 92.83 & 87.59 & 90.27 & 91.13 \\
& $(0.03)$ & $(0.10)$ & $(0.05)$ & $(0.02)$ \\
& 92.12 & 86.25 & 89.33 & 90.29 \\
& $(0.05)$ & $(0.19)$ & $(0.09)$ & $(0.04)$ \\
\hline
\end{tabular}

Note: standard errors in brackets under the means.

Tertiary short term education includes theoretical educations of about 2 years of length. Tertiary medium term education covers bachelor degrees that are very occupation specific, e.g. teachers, nurses, physiotherapists etc.

A significant proportion of the study population is heavily medicated. In the left panel of Figure 1 we show a histogram of patients by the number of different medication groups purchased during the period under observation. A medication group is defined as a subset of pharmaceuticals with identical Anatomical Therapeutic Chemical Classification System (ATC-5) codes. The list of exact codes included in each drug group are presented in Appendix Table A1. Note that even though we concentrate the analysis on users of four specific chronic medication groups, we include all drug groups prescribed to these patients in Figure 1. Strikingly, about $15 \%$ of patients in our sample used as many as 10 or more different types of drug groups. 
Figure 1. Distribution of patients and average adherence by medication load

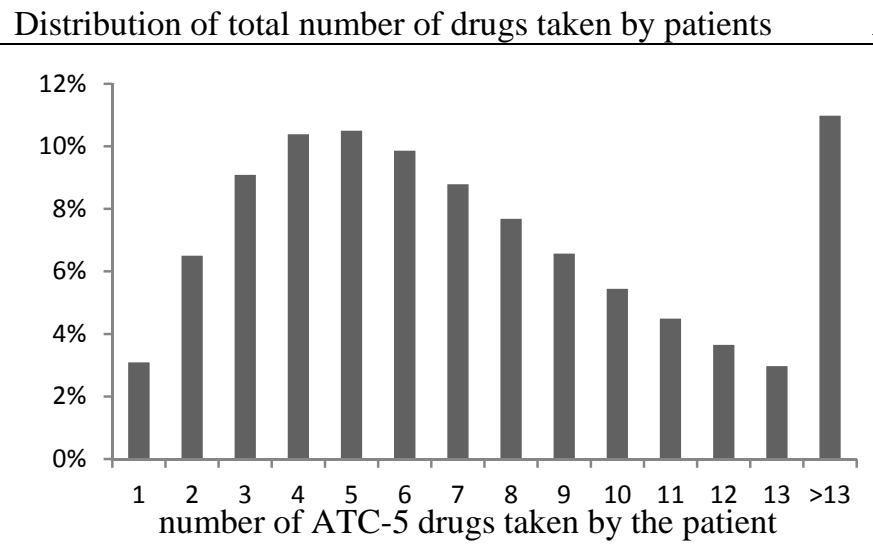
Average adherence by the total number of drugs used

In the right panel of Figure 1 we plot the means of average adherence with individual medication groups as they relate to the total number of different medications prescribed to the patient during the observation window. The total number of drug groups is substantially and positively related to the average adherence rate. For example, a person who takes beta blockers in addition to pills from 3-4 other medication classes is on average 5 percentage points more adherent than someone who takes only beta blockers. It is notable that differences in compliance rates across this dimension are much larger than, for example, differences across educational levels.

Figure 2 considers adherence rates within the context of the doctor-patient relationship. The left panel depicts average adherence by the length of the relationship as measured by total number of prescriptions issued by a given doctor to the patient. We drop pairs where only 1 refill is observed. Pairs that dissolve quickly, after 2 or 3 refills, demonstrate the lowest adherence rates. Among pairs with more refills, adherence rates slowly increase with the length of the relationship. This finding can be attributed to either positive selection (well-functioning doctor-patient pairs are more stable) or to the accumulation of knowledge (longer histories allow doctors to make more informed decisions), or both. The right panel on Figure 2 lends some support to the latter explanation: regardless of the length of the relationship, each successive refill is on average associated with higher adherence. The largest incremental gain in adherence happens in the beginning of the relationship (between the first and fourth refill), with the gradient flattening at later refills. This is consistent with previous evidence: Benner et al (2002) find that dropping out of statin therapy is most likely to happen in the first 6 months. 
Figure 2. Average adherence by length of relationship and by refill number

Average adherence by the total number of refills in a doctor--patient pair

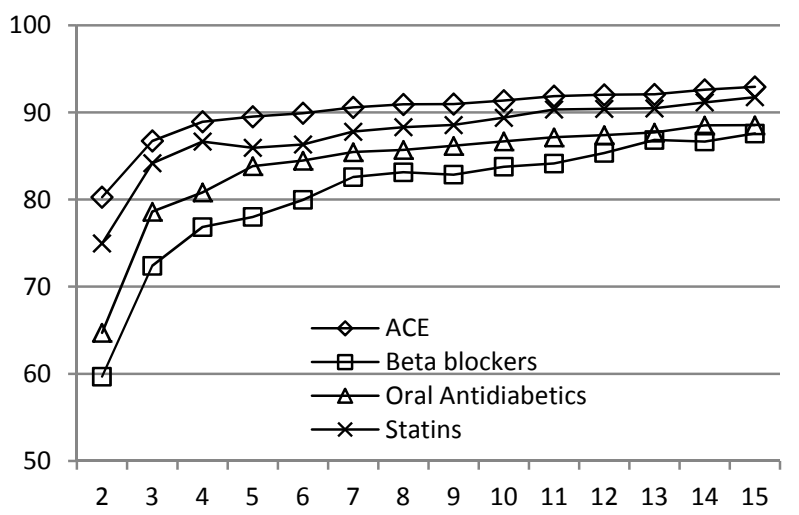

Average adherence by the refill index within a doctor patient pair

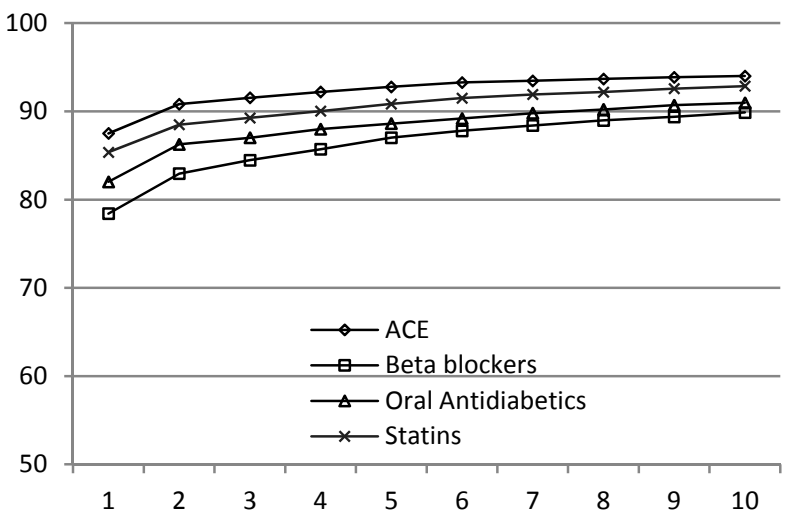

Again we find significant differences in adherence patterns across drug groups. Ace inhibitors and statins start out with initially higher compliance levels and remain on a higher level over time. Beta blockers have the worst initial adherence.

\subsection{Persistence with medication}

An important distinction exists between patients who experience extended periods with no medication supply and patients who may have missed only a few daily doses. The literature differentiates between these cases with the concept of non-persistence, although scientific evidence on the prevalence of non-persistence is generally lacking (RAND, 2009). For the purposes of this study, we define an episode of non-persistence with medication as a period of three or more months with no medication supply. ${ }^{10}$

Consistently with our definition of therapy as being doctor-specific, we do not take into account drugs received by other doctors when identifying periods of non-persistence ${ }^{11}$. In other words, a patient may be non-persistent with respect to the therapy prescribed by one doctor, but persistent with respect to another's - even though we find such cases to be infrequent. Our approach to defining persistence on the level of doctor-patient pair is supported by models of physician-patient

\footnotetext{
${ }^{10}$ Note that we only consider a patient to be "on" a therapy if they have at least two refills in the associated drug group. Thus, we avoid confounding cases of non-persistence with cases of primary non-adherence. Primary non-adherence happens when the patient receives a prescription, obtains the medication, but never refills again, thus dropping out of the treatment altogether.

${ }^{11}$ Simlarly to our adherence measure, we assign "temporary" refills obtained from another doctor to the main doctor. For instance, a sequence of refills may look like "AAA B AA" or "AAA BB AA" - in both cases we assign refills from doctor $B$ to doctor $A$. In this way, we eliminate false instances of non-persistence when the patient is actually seeing a replacement doctor. However, we do no such assignment for the sequence "AAA BBB AA", which will result in one episode of non-persistence w.r.t doctor A.
} 
interaction (e.g. Ma and McGuire, 1997, Chalkley and Khalil, 2005). These models posit that patient demand for treatment responds to physician effort. Thus, one potential interpretation of episodes of non-persistence is as signals of perceived low physician effort, resulting in low demand for treatment.

Similarly to adherence, we define non-persistence on the refill level, taking into account leftover stock of drugs from the previous refill. A typical non-persistent observation is this: on May 28, 2008, a person visits a pharmacy to obtain 4 weeks' supply of medication, while having 2 weeks' supply at home, left from the previous refill. The resulting stock of drugs covers that person until July 8, 2008. However, the next refill is observed only on October 20, 2008, which means the person had no supply of the medication for more than 3 months. Therefore, the current refill (of May 28, 2008) is considered as non-persistent. The persistence variable is not observed for the last refill in a given doctor-patient pair ${ }^{12}$. Doctor-patient pairs that have experienced at least one episode of non-persistence are labeled as "non-persistent”. As we will find out shortly, both definitions (on the patient-doctor match level and on the refill level) of non-persistence are useful.

Non-persistence is fairly common in the data, and for many doctor-patient pairs we observe several instances of non-persistence. Table 4 shows that most refills are persistent, from 93\% for betablockers to $96 \%$ for ace-inhibitors. At the same time, a much larger proportion of doctor-patient pairs is affected by non-persistence. For example, among beta blockers, as many as 58\% of pairs have experienced at least one prolonged break in therapy. Taken together, these findings imply that instances of non-persistence are not concentrated in a few "problematic" doctor-patient pairs, but rather are distributed across all pairs. Note also that switching between doctors is institutionally costly in Denmark, and thus episodes of non-persistence with one physician are typically not due to the patient temporarily switching to another doctor, but rather reflect a complete break from therapy.

Table 4. Prevalence of non-persistence among refills and doctor-patient pairs

\begin{tabular}{lllll}
\hline & ACE & Beta blockers & $\begin{array}{l}\text { Oral } \\
\text { Antidiabetics }\end{array}$ & Statins \\
\hline Non-persistence across doctor-patient pairs & & & & \\
Non-persistent pairs & 184,026 & 35,285 & 77,356 & 315,555 \\
Persistent pairs & 503,149 & 49,110 & 165,886 & 609,740 \\
\hline
\end{tabular}

${ }^{12}$ In principle, one may declare the last refill as being non-persistent, because it signifies an (infinite) break in therapy. We do not take this view as we cannot hypothesize why the pair has broken up. 


\begin{tabular}{lllll}
\hline $\begin{array}{l}\text { Share of persistent pairs } \\
\text { Non-persistence across refills }\end{array}$ & $73 \%$ & $58 \%$ & $68 \%$ & $66 \%$ \\
Non-persistent refills & & & & \\
Persistent refills & 248,126 & 65,037 & 112,675 & 451,092 \\
Share of persistent refills & $6,540,763$ & 824,139 & $3,368,489$ & $8,342,342$ \\
\hline
\end{tabular}

The next table provides further insight into the degree to which doctor-patient pairs are affected by non-persistence. For such pairs, we identify "episodes of care” as strings of successive refills uninterrupted by non-persistence. By definition, non-persistent pairs have at least 2 episodes of care. Table 5 presents a breakdown of non-persistent pairs by the number of episodes of care. For instance, out of 184,026 pairs that are non-persistent for ace inhibitors (see Table 4), 75.7\% have only one non-persistent refill, while $17.4 \%$ pairs have three episodes of care, or two instances of non-persistence. Two or three instances of non-persistence is by far the most frequent occasion; pairs with more frequent breaks in therapy are rare.

Table 5. Distribution of non-persistent doctor-patient pairs by the number of episodes of care

\begin{tabular}{llllll}
\hline $\begin{array}{l}\text { Number of } \\
\text { episodes of } \\
\text { care }\end{array}$ & $\begin{array}{l}\text { Number of } \\
\text { instances of non- } \\
\text { persistence }\end{array}$ & ACE & Beta blockers & Oral Antidiabetics & Statins \\
\hline 2 & 1 & $75.7 \%$ & $60.7 \%$ & $70.2 \%$ & \\
3 & 2 & $17.4 \%$ & $19.6 \%$ & $19.8 \%$ & $70.3 \%$ \\
4 & 3 & $4.7 \%$ & $8.8 \%$ & $6.4 \%$ & $20.3 \%$ \\
5 & 4 & $1.5 \%$ & $4.7 \%$ & $2.2 \%$ & $2.3 \%$ \\
6 & 5 & $0.5 \%$ & $2.6 \%$ & $0.9 \%$ & $0.7 \%$ \\
$>6$ & $>5$ & $0.3 \%$ & $3.7 \%$ & $0.5 \%$ & $0.4 \%$ \\
Total & Total & $100 \%$ & $100 \%$ & $100 \%$ & $100 \%$ \\
\hline
\end{tabular}

\subsection{Relationship between adherence and persistence}

The first and third column in Table 6 show that differences in average medication adherence rates among persistent and non-persistent doctor-patient pairs are large: from 14 to 18 percentage points, depending on the drug group. Since refills associated with non-persistence have by definition close to zero MPR, it is not surprising that doctor-patient pairs affected by non-persistence demonstrate lower average adherence rates than those that are not. A less obvious result is presented in columns (E) and (F), which contain average adherence rates among persistent refills within non-persistent doctor-patient pairs. Most refills in non-persistent pairs are actually adherent, i.e. they were made relatively on time. We find that average adherence is lower in (E) than in (A), although the 
difference is smaller than the one between (A) and (C). This finding implies that the definition of non-persistence on the level of the doctor-patient pair is informative: even a single instance of nonpersistence in a doctor-patient relationship is enough to signal a somewhat different adherence dynamic.

Table 6. Summary statistics of adherence by persistence

\begin{tabular}{lcc|cccc}
\hline & \multicolumn{2}{c|}{ persistent pairs } & \multicolumn{4}{c}{ non-persistent pairs } \\
\hline & \multicolumn{2}{c|}{ all refills } & \multicolumn{3}{c}{ all refills } & \multicolumn{2}{c}{ persistent refills } \\
& Mean & \% full adherence & Mean & \% full adherence & Mean & \% full adherence \\
Ace inhibitors & 96.49 & $77 \%$ & 86.68 & $60 \%$ & 94.04 & $67 \%$ \\
& $(0.01)$ & $(0.00)$ & $(0.02)$ & $(0.00)$ & $(0.01)$ & $(0.00)$ \\
Beta blockers & 94.65 & $71 \%$ & 79.84 & $49 \%$ & 88.62 & $57 \%$ \\
& $(0.02)$ & $(0.00)$ & $(0.06)$ & $(0.00)$ & $(0.04)$ & $(0.00)$ \\
Hypoglycemics & 94.24 & $72 \%$ & 84.63 & $57 \%$ & 90.48 & $62 \%$ \\
& $(0.01)$ & $(0.00)$ & $(0.03)$ & $(0.00)$ & $(0.02)$ & $(0.00)$ \\
Statins & 95.84 & $68 \%$ & 85.02 & $51 \%$ & 93.23 & $59 \%$ \\
& $(0.00)$ & $(0.00)$ & $(0.01)$ & $(0.00)$ & $(0.01)$ & $(0.00)$ \\
\hline
\end{tabular}

Note: standard errors in brackets under the means

Further illustration of differences between persistent and non-persistent doctor-patient pairs is presented in Figure 3, which plots cumulative distributions of refill-based adherence rates for beta blockers (percentiles on horizontal axis, and adherence rate on vertical axis). For illustration purposes, we include only "imperfect" refills, i.e. those with less than 100\% adherence. Among these refills, the median adherence rate is $30 \%$ if all doctor-patient pairs are considered, and this rate falls to $15 \%$ among non-persistent pairs. Above we found that even a single incidence of nonpersistence in a doctor-patient relationship is correlated with lower average adherence; from Figure 3 we additionally find that the effect is particularly pronounced in the lower part of the distribution, among pairs who already have issues with non-adherence. 
Figure 3. CDF of adherence with beta blockers among all and persistent doctor-patient pairs. Only refills with $<100 \%$ adherence shown.

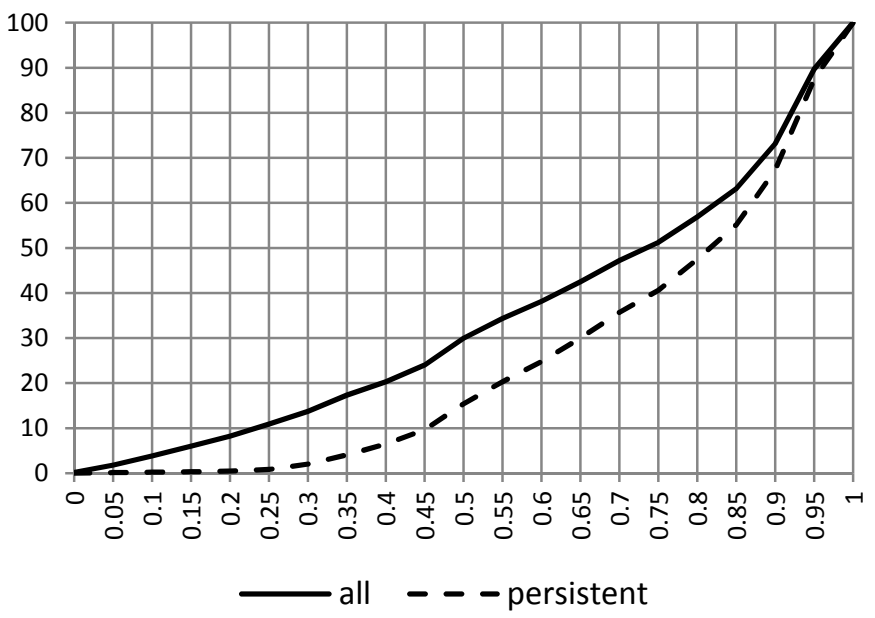

\section{Two-way analysis of variation in adherence}

\subsection{Model}

We begin with a general question: what is the relative patient- and doctor-specific contribution to the observed variability in patient compliance with prescribed therapy across doctor-patient matches, and what portion of the residual variation is specific to the doctor-patient pair? There are four major contributors to the variation in adherence rates. In the following table, we identify these factors, together with appropriate measurements that can be taken given the available data:

Table 7. Factors of adherence: conceptual framework

\begin{tabular}{|c|c|c|}
\hline Factor of adherence & Measurement & Interpretation \\
\hline $\begin{array}{l}\text { (A) Patient-specific } \\
\text { compliance behavior }\end{array}$ & Patient fixed effect & $\begin{array}{l}\text { The propensity of an individual } \\
\text { patient to adhere to medication } \\
\text { prescriptions, across doctors and } \\
\text { time; }\end{array}$ \\
\hline $\begin{array}{l}\text { (B) Doctor-specific influence } \\
\text { on patient adherence }\end{array}$ & Doctor fixed effect & $\begin{array}{l}\text { If doctor A is more capable of } \\
\text { inducing compliance in her patients } \\
\text { than doctors B and C, then that } \\
\text { doctor A's-own contribution will } \\
\text { appear as the difference between } \\
\text { average compliance across patients } \\
\text { of doctor A and total average } \\
\text { compliance rate (across A, B and C); }\end{array}$ \\
\hline $\begin{array}{l}\text { (C) Doctor-patient match } \\
\text { quality }\end{array}$ & $\begin{array}{l}\text { Average compliance across } \\
\text { all refills within a particular } \\
\text { doctor-patient pair, net of } \\
\text { controlling for individual } \\
\text { influences of the doctor and }\end{array}$ & $\begin{array}{l}\text { The quality of doctor-patient } \\
\text { relationship will result in positive or } \\
\text { negative complementarities between } \\
\text { doctor's and patient's own } \\
\text { adherence styles. As a result, the }\end{array}$ \\
\hline
\end{tabular}


the patient (components (a) and (b))

(D) Changes in the course of therapy and doctor-patient relationship
Deviation of compliance with individual refills from the average compliance in a given doctor-patient pair; adherence in a given doctor-patient pair will deviate from the level predicted by factors (A) and (B) alone.

Possible factors include: improvements in health status; building trust; accumulation of doctor knowledge about the patient, etc.

Mathematically, these factors can be combined into a model of adherence in the following way

$$
Y_{i j t}=\delta_{i}+\gamma_{j}+\sigma_{i j}+\epsilon_{i j t}
$$

Where $\delta_{i}$ - patient fixed effect (component (a)), $\gamma_{j}$ - doctor fixed effect (component (b)), $\sigma_{i j}-$ doctor-patient match quality (component (c)) and $\varepsilon_{i j t}$ - deviation of compliance with refill $t$ from the average compliance within the doctor-patient pair (component (d)). A portion of the matchspecific component $\sigma_{i j}$ can be explained by our match-specific controls $X_{i j t}$, so that equation (1) becomes:

$$
Y_{i j t}=\delta_{i}+\gamma_{j}+\beta X_{i j t}+\eta_{i j t}
$$

In practice, the estimation of equation (2) is achieved by including both patient and doctor fixed effects, whose estimates are denoted by $\hat{\delta}_{i}$ and $\hat{\gamma}_{j}$. With that, the other parameters in equation (1) can be expressed as:

$$
\begin{gathered}
\hat{\sigma}_{i j}=\frac{1}{T_{i j}} \sum\left(Y_{i j t}-\hat{\delta}_{i}-\hat{\gamma}_{j}\right) \\
\hat{\epsilon}_{i j t}=Y_{i j t}-\hat{\sigma}_{i j}-\hat{\gamma}_{j}
\end{gathered}
$$

The two-way fixed effects models of the type (2) have been extensively used in labor economics (see, e.g., Abowd et al. (1999), Abowd et al. (2008)), but have not yet received wide adoption in the doctor-patient setting (with an exception of Bennett et al. $(2011)^{13}$ ). Medical studies have largely adhered to multi-level analysis (see, e.g. Sixma et al $(1998)^{14}$ ), where the outcome variable is

\footnotetext{
${ }^{13}$ Abowd, J. M., F. Kramarz, and D. N. Margolis, 1999, High wage workers and high wage firms. Econometrica 67 (2), 251-334.

Abowd, J.M., F. Kramarz and S.D. Woodcock 2008, Econometric Analyses of Linked Em-ployer-Employee Data, in: L. Mátyás, P. Sevestre (Eds.), The Econometrics of Panel Data, Chapter 22. Springer, Heidelberg, pp. 727-759.

Daniel Bennett, Che-Lun Hung, Tsai-Ling Lauderdale (2011), "Health Care Competition and Antibiotic Use in Taiwan”, working paper, University of Chicago

${ }^{14}$ Sixma, Spreeuwenberg, and van der Pasch. Patient satisfaction with the general practitioner: a two-level analysis. Medical Care: 1998, 36(2), p. 212-229
} 
modeled as a result of GP-level factors and patient-level factors. Such models typically assume oneway nests as a set of patients within a GP. Therefore, they cannot accommodate for changes in patient outcomes due to switching between GP's. As we have seen previously, average adherence rates do change substantially when a patient changes doctors, contributing to the total variation in adherence. Multi-level models miss those changes and may come to erroneous conclusions regarding the relative contributions of patient- and doctor-level factors to the total variation.

Another advantage of the two-way fixed effect model is the higher efficiency of estimates of factors related to the match value, as well as factors related to time variation in adherence rates. This is due to the fact that all observed and unobserved patient-level factors are accounted for by the patient fixed effect. In contrast, multi-level models do not allow for such a regressor, as it is not identified within their structure (outcomes of patient A across doctors B and C are assumed to be independent). With all these advantages, a two-way fixed effects model places higher demands on the quality of the data: it requires a panel dataset with sufficient amount of doctor switching in order to identify the doctor's and patient's own adherence styles ${ }^{15}$.

\subsection{Graphical illustration of results from the two-way fixed effects model}

The estimation of equation (3) results in as many estimated parameters $\gamma_{i}$ as there are primary care doctors in the Danish health care system (minus one, as all doctor fixed effects are normalized relative to the reference doctor). Doctor fixed effects are measured in the same units as adherence rates, i.e. between $0 \%$ and $100 \%$. These parameters capture the effects of individual heterogeneity among physicians that affects all their patients in the same way. If physicians exert strong influence on their patients' adherence decisions, then some of them will have larger values of $\gamma_{i}$ than others.

Figure 4 plots the distribution of estimated doctor fixed effects in the population, separately for each drug group (normalized to zero for better comparison). Most values are within $+/-5$ percentage points from the average: a patient will gain 5 percentage points in adherence by switching from the average to the best doctor. This is a large gain: for instance, it is sufficient to overcome the mean adherence gap associated with age or birth origin (reported in Table 2).

The density plots in Figure 4 suggest that the amount of heterogeneity in doctor influences varies across drug groups. For statins, the distribution is most concentrated around zero, meaning that a smaller percentage of doctors are substantially away from the average. In contrast, the distribution

\footnotetext{
${ }^{15}$ See Abowd et al. (2008) for more detailed discussion of the identification.
} 
for beta blockers has the largest variance, suggesting high degree of differentiation in physician's influence on compliance. In other words, compliance with beta blockers will improve more relative to compliance with statins if under-performing patients are matched with better doctors. Indeed, medications within this group are more likely to have immediately noticeable side effects, and might require more careful drug choice based on the individual patient's needs. In general, differences in physician-level effects across drug groups imply that different health conditions present varying challenges to physician authority and that a one-size-fits all approach to evaluating physician input into the compliance decision is not accurate.

Figure 4. Density plots of average physician-level contribution to patient compliance by drug type

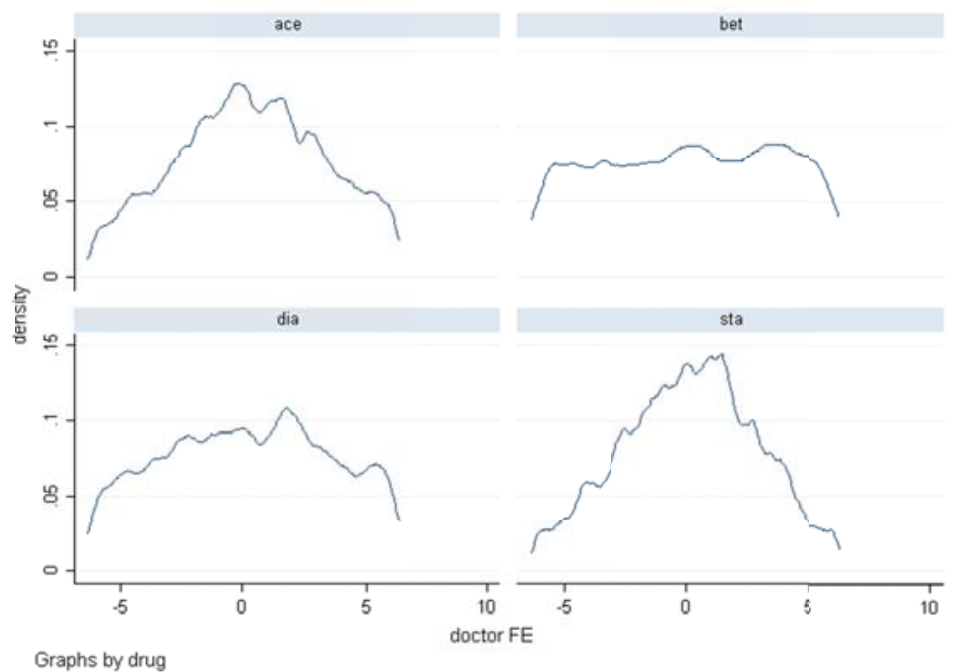

Combining the estimates of parameters $\delta_{i}$ and $\gamma_{i}$ for the actual doctor-patient pairs, we illustrate the features of the matching process in the Danish healthcare system. Figure 5 shows a scatter plot of actual doctor-patient pairs, with patient fixed effects on the horizontal, plotted against the fixed effect estimated for the matching doctor, on the vertical axis. The difference between the highest and the lowest points in the scatter plots is indicative of the heterogeneity of physician-level contributions to adherence, and mirrors the results on Figure 4. The distance between the left and right borders of the plots is representative of the heterogeneity in patient-level time-invariant characteristics that affect adherence. Beta blockers stand out among other drugs in that both patientand doctor-level aspects of heterogeneity are larger.

Most of the dots are located within negatively sloped bands. However, this is only a mechanical consequence of adherence being bounded between 0 and 100, and does not indicate negative 
matching between doctors and patients. A negative matching pattern would be seen in the distribution of density, where most population lies either in the north-west or south-east quadrants. To investigate this, we augmented the scatter plots with density information, with darker areas corresponding to higher density areas. We find no evidence of negative matching in the Danish health care system.

Figure 5. Scatterplot of actual doctor-patient matches

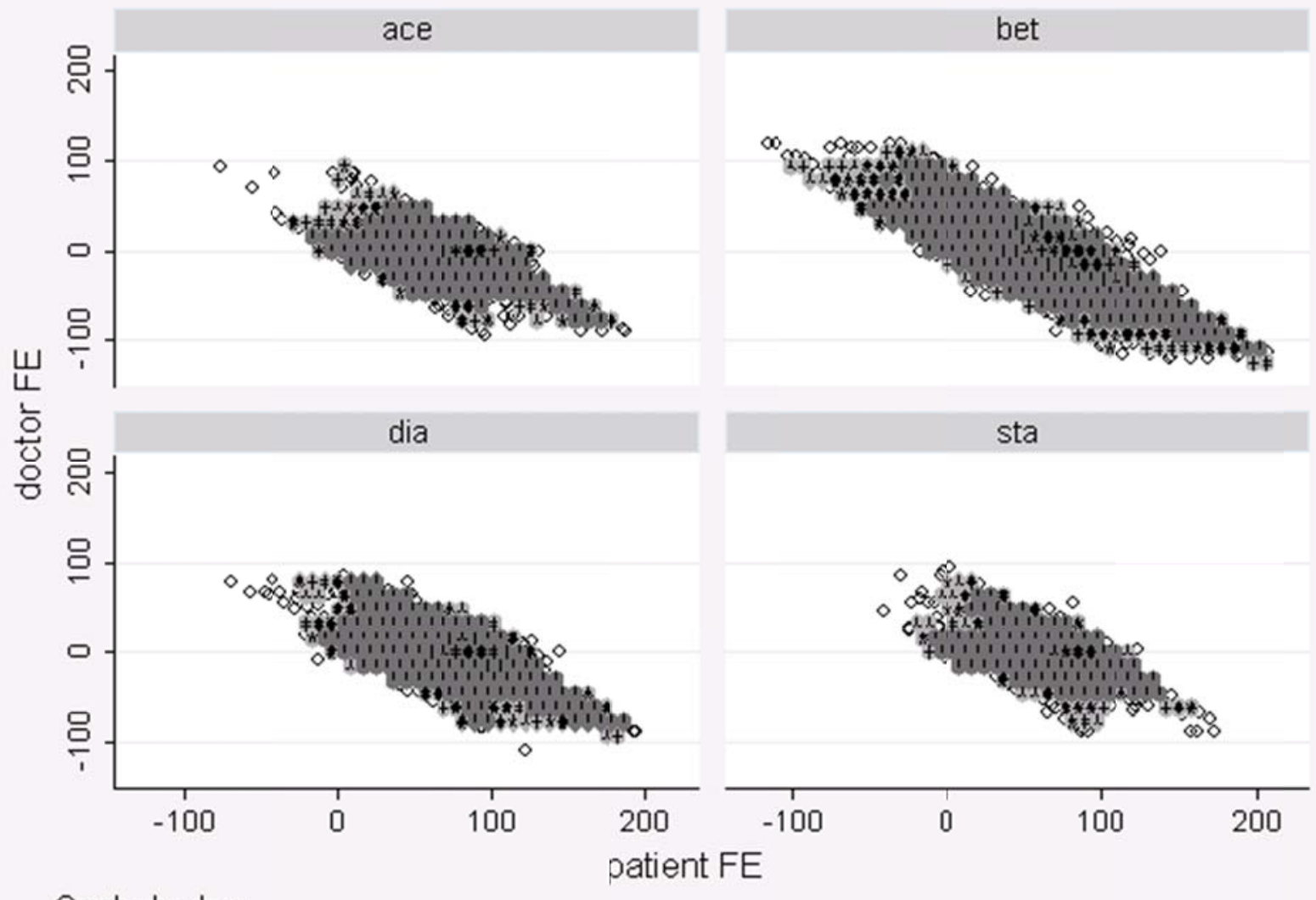

Graphs by drug

\subsection{Variance decomposition of patient adherence}

We now turn to the evaluation of relative contributions of the four groups of factors of adherence patient, doctor, match and drug-specific - identified in Table 7. For convenience, we reproduce the empirical model here:

$$
Y_{i j t}=\delta_{i}+\gamma_{j}+\sigma_{i j}+\epsilon_{i j t}
$$

At the first step, we abstract from the inter-temporal variation in adherence, and focus on the variation in average adherence across doctor-patient pairs. Such variation is given by $V\left(\delta_{i}+\gamma_{j}+\right.$ 
$\left.\sigma_{i j}\right)$ and summarizes time-invariant factors of adherence: the doctor's and patient's own styles, as well as the match quality. Using estimates of the model (4), we compute data variances of each component: $V\left(\hat{\delta}_{i}\right), V\left(\hat{\gamma}_{j}\right), V\left(\hat{\sigma}_{i j}\right)$. Note that generally the total variance of adherence is less than the variance of its components: $V\left(\hat{\delta}_{i}+\hat{\gamma}_{j}+\hat{\sigma}_{i j}\right)<V\left(\hat{\delta}_{i}\right)+V\left(\hat{\gamma}_{j}\right)+V\left(\hat{\sigma}_{i j}\right)-$ because doctor and patient fixed effects are negatively correlated (see Figure 5). Therefore we instead relate individual variances $V\left(\hat{\delta}_{i}\right), V\left(\hat{\gamma}_{j}\right), V\left(\hat{\sigma}_{i j}\right)$ to their sum, separately for each drug group. Results are shown in the following table.

Table 8. Decomposition of the total variance into patient and doctor-specific components

\begin{tabular}{llll}
\hline & Patient & Doctor & Match \\
\hline ACE inhibitors & $59.8 \%$ & $12.5 \%$ & $27.7 \%$ \\
Beta blockers & $59.9 \%$ & $36.6 \%$ & $3.6 \%$ \\
Oral Antidiabetics & $54.6 \%$ & $20.0 \%$ & $25.4 \%$ \\
Statins & $62.6 \%$ & $8.2 \%$ & $29.2 \%$ \\
\hline
\end{tabular}

Patient heterogeneity is the largest contributor to the variation in therapy compliance across doctorpatient pairs. Doctor's influence and match quality take the back seat, and their relative contributions vary across drug groups. Beta blockers and statins stand out as two extremes. For beta blockers, doctor quality picks up the variance not explained by the patient's own behavior, while match quality does not seem to matter much. For statins, the match quality is very important, while the doctor's identity does not explain much of variation across pairs. In other words, there is a clear quality "sorting" of doctors when it comes to adherence to beta blockers: moving a given patient to a "better" doctor will most likely result in higher adherence. This does not apply to statins and to some extent to ace inhibitors: for those drugs, one needs to know factors of the doctor-patient relationship in order to predict whether adherence will improve upon moving from one doctor to another.

We then turn to the evaluation of inter-temporal variation in adherence, and its contribution to the total variation of refill-based MPR. With the raw data averages, we have seen substantial changes in adherence across the cumulative number of refills (see Figure 2). However, raw data means must be interpreted with caution, as selection is likely to play a role. The two-way fixed effects model delivers a more precise measure of adherence dynamics, after doctor's and patient's own styles are controlled for. 
From the evidence presented in Table 9, it is clear that the dynamics of compliance with therapy over the course of the doctor-patient relationship plays a major role in the total variation of adherence rates: $56-57 \%$ of total variation is attributed to fluctuations of refill-based adherence rates around the pair's average (for beta blockers the associated number is $42 \%$ ).

Table 9. Within-pair and across-pairs variation in adherence rates

\begin{tabular}{llll}
\hline & $\begin{array}{l}\text { Variance of adherence } \\
\text { on refill level }\end{array}$ & $\begin{array}{l}\text { Variance of within- } \\
\text { pair deviations }\end{array}$ & $\begin{array}{l}\text { Variance of pair- } \\
\text { specific means }\end{array}$ \\
\hline ACE inhibitors & $100 \%$ & $56.6 \%$ & $43.4 \%$ \\
Beta blockers & $100 \%$ & $42.1 \%$ & $57.9 \%$ \\
Oral antidiabetics & $100 \%$ & $56.3 \%$ & $43.7 \%$ \\
Statins & $100 \%$ & $57.0 \%$ & $43.0 \%$ \\
\hline
\end{tabular}

More than half of the observed variation in refill based adherence cannot be explained by the individual-specific effects of doctors and patients, or any other time-invariant characteristics, such as individual compatibility. This suggests that there is great potential for improvement of adherence rates without breaking the existing doctor-patient pairs: for example, by monitoring and preventing instances of non-persistence or by facilitating communication between doctors and patients.

\section{Investigating factors affecting compliance}

\subsection{Econometric strategy}

Patient adherence is crucial for the success of any prescribed therapy and can be thought of as a component of the patient's investment in health. Studies have demonstrated that the decision to comply with doctor's orders depends on the physician- and patient-level factors which are constant across time, and on contextual variables. The latter include the level of familiarity between the physician and the patient, patient knowledge about the medical condition and the therapy, and other potentially unobservable time-varying characteristics (RAND, 2009; Osterberg and Blasche, 2005; Krueger et al, 2005; Haynes et al, 2002). We postulate an empirical model of medication compliance that takes into account the different groups of factors:

$$
Y_{i j t}=c+\beta_{1} P_{i t}+\beta_{2} D_{j}+\beta_{3} X_{i j t}+\epsilon_{i j t_{i}} \text { (5) }
$$

where $i$ indexes the patient, $j$ indexes the doctor, and $t$ is the refill index (and also time index when refill occurred). The outcome variable is $Y_{i j t}$ - the medication possession ratio (MPR) for that particular refill. The set of explanatory variables includes $P_{i t}$ - the patient's demographic and socio- 
economic characteristics as well as time varying characteristics: education, gender, birth origin, annual income, age. In addition, $P_{i t}$ also includes variables related to Danish subsidy schemes as they affect the particular patient $i$ at time t: subsidy month (the month in the yearly subsidy cycle, which does not coincide with calendar year), subsidy year (number of years for which subsidy was received), the price of the drug (as measured in DKK for 1 days' supply), and an indicator for the first year of a particular treatment (a new patient). Further, $D_{j}$ represents a set of doctor fixed effects.

Finally, the set of controls $X_{i j t}$ includes match-specific variables: whether the drug was prescribed by the main physician and the number of previous visits associated with the same medication therapy. The model is estimated by pooling data together and adding dummies for drug groups (ace inhibitor, beta blocker, statin or anti-diabetic).

The inclusion of drug price into the adherence equation (5) deserves further discussion. The OLS estimate of the effect of drug price on adherence could be biased for a number of reasons. Even though the shelf price of medications is centrally set by the government every two weeks, the actual price paid by the patient is affected by the amount of government subsidy received by that person. Figure 6 illustrates the relationship between the shelf and the actual price in DKK per day's supply of the medication paid by the patient over the subsidy year, for the four types of medications. The blue dots show the average user price in DKK over the course of the subsidy year. The red dots show the average government set price. The user price decreases over the course of the subsidy year relative to the government price, as the patient's consumption of drugs accumulates. The average shelf price for a daily dose of medication is 2.9 DKK. The average out of pocket price is only 0.71 DKK. Appendix Table A2 presents the main descriptive statistics of the shelf- and out-of-pocket prices observed in the data. 
Figure 6. Actual and sticker prices of pharmaceuticals

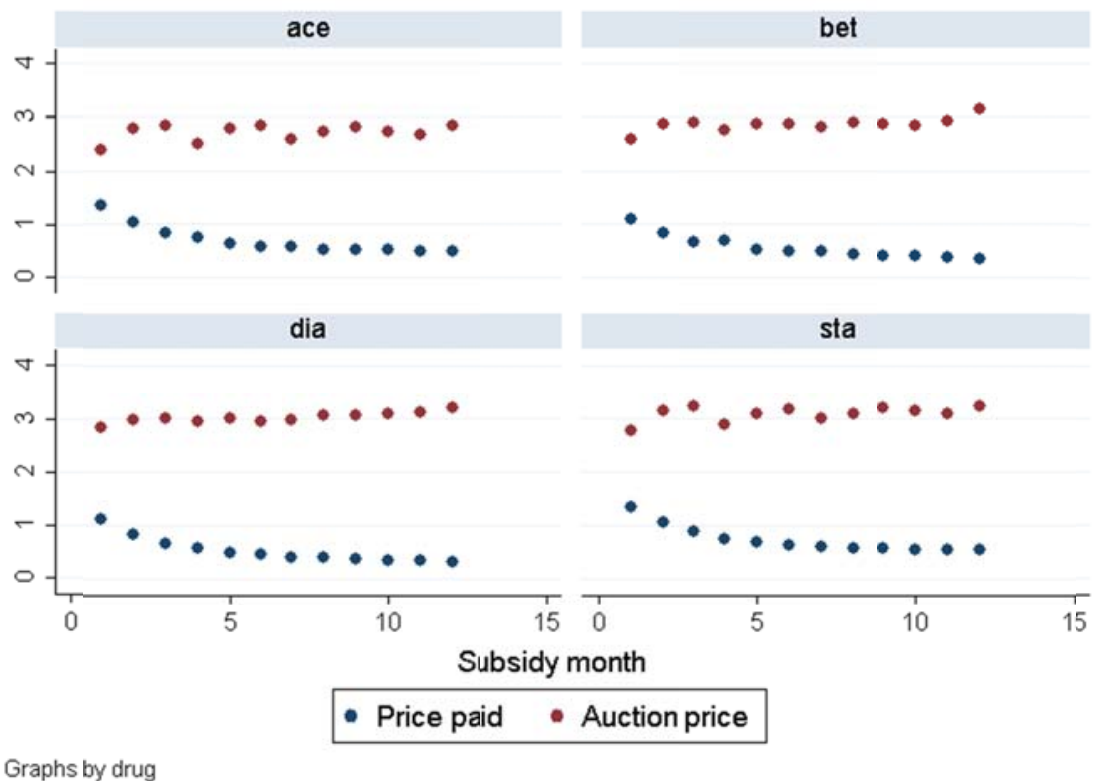

The discount given by the government is increasing with the accumulated volume of consumed drugs - of whatever group - bought since the beginning of the subsidy cycle (year). Therefore, a patient who has more health conditions and consumes more medications will be paying a lower price than a healthier person. In Figure 1 we have shown that adherence rates rise with the total number of ATC-5 medication groups taken by the patient. Moreover, there is also a direct, mechanical effect of price on adherence: a more adherent patient buys more drugs and receives a more generous co-insurance rate from the government. As a result, we may find a negative effect of price on adherence, even if none exists.

To correct for these sources of bias, we use an instrumental variables approach in a two-stage least squares framework. In the first stage we instrument for the price paid by the patient with the government-set shelf price determined by the government auction, an indicator for the first month of the subsidy cycle the patient is currently in, and the interaction between the two. The shelf price set by the government is centrally controlled, it is identical in all pharmacies during a two-week period and cannot be affected by the patient's health investments. The number of months that have elapsed since the first purchase in the patient's current subsidy year is also unlikely to be correlated with patient adherence on a particular refill. The first stage estimates are reported in Table A3 in the Appendix. The auction price set by the government, the indicator for the first month in the new subsidy cycle, and their interaction are positively correlated with the out-of-pocket price paid by the 
patient. All instrumental variables are statistically significantly correlated with the out-of-pocket price with t-statistics exceeding 100.

\subsection{Regression results}

In Table 10 we present results from several specifications of the empirical model of compliance, following equation (5) above. Column (1) includes only patient-level controls, to which in column (2) we add refill-level characteristics such as whether the prescription was written by the main doctor, and an indicator for a refill written to a new patient. Further, in column (3) we add physician fixed effects, which control for unobserved and time-invariant physician characteristics. Finally, column (4) presents the results from the 2SLS specification of the physician fixed effects model in (3), with a correction for potential endogeneity of drug price.

Beta blockers have much lower average adherence than any other medication class, followed by oral hypoglicemics. Differences in adherence across demographic groups exhibit similar patterns to what has been found in previous studies: older people are more likely to comply with prescribed therapy, men have slightly more trouble keeping with the therapy regimen than women. Quantitatively, the age gradient is quite strong (approximately two percentage points gain in adherence for every 10 years), particularly at younger ages. Immigrants are less adherent than Danes even after we include controls for socio-economic characteristics: they have on average two percentage points lower adherence levels. This effect is smaller than the differences in sample means between immigrants and Danes (see Table 2), but is nevertheless economically large and remains so even after doctor fixed effects are included.

A different story emerges with respect to education and income. In the simple means presented in Table 3, we found a negative relationship between income and adherence. As models (1) and (2) show, including other patient controls, such as age (which itself is positively correlated with income) does not alter this monotonicity. This finding is somewhat surprising, as US-based studies typically (but not always) find a positive relationship between income and adherence, as well as between education and adherence (DiMatteo, 2004). The model estimates in column (3) suggest a possible explanation: negative matching between higher income patients and doctors. Indeed, once doctor fixed effects are included, the relation between income and adherence disappears. The interpretation is that well-to-do patients form matches with physicians whose patients on average 
exhibit lower adherence levels. The reasons for the assortative matching are unclear - in the Danish context, income has almost no relation to access to care - and remain a question for future study.

A further insight in the effect of doctor-patient matching is provided by the "main doctor" variable, which is an indicator for the doctor from whom the patient has received the largest number of refills in the current year. Compliance with the main doctor is on average 2.7pp higher than with secondary doctors. A related result is that doctor-patient pairs with larger number of refills also demonstrate higher levels of adherence.

Table 10. Determinants of patient compliance with medication. Dependent variable: refill-based adherence with medication

\begin{tabular}{|c|c|c|c|c|c|}
\hline & & $\begin{array}{c}\text { OLS } \\
\text { (1) }\end{array}$ & $\begin{array}{c}\text { OLS } \\
(2)\end{array}$ & $\begin{array}{c}\text { OLS-FE } \\
\text { (3) }\end{array}$ & $\begin{array}{c}2 S L S-I V \\
(4)\end{array}$ \\
\hline \multirow[t]{6}{*}{ Drug } & \multirow[t]{2}{*}{ Beta blockers } & $-3.981 * * *$ & $-4.455^{* * *}$ & $-4.456 * * *$ & $-4.475 * * *$ \\
\hline & & $(0.0237)$ & $(0.0232)$ & $(0.0234)$ & $(0.0234)$ \\
\hline & \multirow[t]{2}{*}{ Hypoglicemics } & $-2.427 * * *$ & $-3.981 * * *$ & $-3.925 * * *$ & $-3.938 * * *$ \\
\hline & & $(0.0133)$ & $(0.0132)$ & $(0.0133)$ & $(0.0134)$ \\
\hline & \multirow[t]{2}{*}{ Statins } & $-1.684 * * *$ & $-1.231 * * *$ & $-1.238 * * *$ & $-1.210 * * *$ \\
\hline & & $(0.00990)$ & (0.00973) & (0.00982) & $(0.00987)$ \\
\hline \multirow[t]{2}{*}{ Drug price } & \multirow[t]{2}{*}{ Out of pocket price/ daily dose } & $-0.808^{* * *}$ & $-0.939 * * *$ & $-0.896 * * *$ & $-1.013^{* * *}$ \\
\hline & & $(0.00329)$ & $(0.00323)$ & $(0.00324)$ & $(0.00772)$ \\
\hline \multirow[t]{12}{*}{ Education } & \multirow[t]{2}{*}{ Less than high school } & $-0.428 * * *$ & $-0.393 * * *$ & $-0.411^{* * *}$ & $-0.410 * * *$ \\
\hline & & $(0.0201)$ & $(0.0197)$ & $(0.0199)$ & $(0.0200)$ \\
\hline & \multirow[t]{2}{*}{ High School } & $-1.253^{* * *}$ & $-0.857 * * *$ & $-0.627 * * *$ & $-0.613^{* * *}$ \\
\hline & & $(0.0391)$ & $(0.0382)$ & $(0.0385)$ & $(0.0386)$ \\
\hline & \multirow[t]{2}{*}{ Vocational } & $-0.778 * * *$ & $-0.497 * * *$ & $-0.430 * * *$ & $-0.418^{* * *}$ \\
\hline & & $(0.0208)$ & $(0.0204)$ & $(0.0206)$ & $(0.0207)$ \\
\hline & \multirow[t]{2}{*}{ Tertiary short term } & $-0.873 * * *$ & $-0.472 * * *$ & $-0.408 * * *$ & $-0.390 * * *$ \\
\hline & & $(0.0340)$ & $(0.0333)$ & $(0.0335)$ & $(0.0336)$ \\
\hline & \multirow[t]{2}{*}{ Tertiary medium term } & $-0.723 * * *$ & $-0.387 * * *$ & $-0.317 * * *$ & $-0.305^{* * *}$ \\
\hline & & $(0.0247)$ & $(0.0242)$ & $(0.0244)$ & $(0.0245)$ \\
\hline & \multirow[t]{2}{*}{ Academic } & $-1.131^{* * *}$ & $-0.662 * * *$ & $-0.419 * * *$ & $-0.404 * * *$ \\
\hline & & $(0.0341)$ & $(0.0334)$ & $(0.0338)$ & $(0.0339)$ \\
\hline \multirow[t]{2}{*}{ Gender } & \multirow[t]{2}{*}{ Male } & $-0.360 * * *$ & $-0.352 * * *$ & $-0.403 * * *$ & $-0.403 * * *$ \\
\hline & & (0.00909) & $(0.00890)$ & $(0.00900)$ & $(0.00903)$ \\
\hline \multirow[t]{2}{*}{ Birth origin } & \multirow[t]{2}{*}{ Foreign born } & $-2.007 * * *$ & $-1.734 * * *$ & $-1.496 * * *$ & $-1.492^{* * *}$ \\
\hline & & $(0.0263)$ & $(0.0258)$ & $(0.0261)$ & $(0.0262)$ \\
\hline \multirow{6}{*}{ Income Quartile } & \multirow[t]{2}{*}{ Second } & $0.237 * * *$ & $-0.090 * * *$ & $-0.066 * * *$ & $-0.069 * * *$ \\
\hline & & $(0.0125)$ & $(0.0122)$ & $(0.012)$ & $(0.0123)$ \\
\hline & \multirow[t]{2}{*}{ Third } & -0.0132 & $-0.069 * * *$ & $-0.037 * * *$ & -0.0140 \\
\hline & & $(0.0130)$ & $(0.0127)$ & $(0.0127)$ & $(0.0128)$ \\
\hline & \multirow[t]{2}{*}{ Fourth } & $-0.460 * * *$ & $-0.213^{*} * *$ & $-0.132 * * *$ & $-0.100 * * *$ \\
\hline & & $(0.0147)$ & $(0.0144)$ & $(0.0145)$ & $(0.0147)$ \\
\hline \multirow[t]{4}{*}{ Age } & \multirow[t]{2}{*}{30 to 40} & $3.485^{* * *}$ & $2.098 * * *$ & $2.017 * * *$ & $2.004 * * *$ \\
\hline & & $(0.0956)$ & $(0.0936)$ & $(0.0936)$ & $(0.0940)$ \\
\hline & \multirow[t]{2}{*}{40 to 50} & $6.239 * * *$ & $4.232 * * *$ & $4.200 * * *$ & $4.183^{* * *}$ \\
\hline & & $(0.0901)$ & $(0.0882)$ & $(0.0882)$ & $(0.0886)$ \\
\hline
\end{tabular}




\begin{tabular}{|c|c|c|c|c|c|}
\hline & 50 to 60 & $\begin{array}{l}8.355 * * * \\
(0.0891)\end{array}$ & $\begin{array}{l}5.884 * * * \\
(0.0873)\end{array}$ & $\begin{array}{l}5.872 * * * \\
(0.0873)\end{array}$ & $\begin{array}{l}5.842 * * * \\
(0.0878)\end{array}$ \\
\hline & 60 to 70 & $\begin{array}{l}9.572 * * * \\
(0.0889)\end{array}$ & $\begin{array}{l}6.894 * * * \\
(0.0871)\end{array}$ & $\begin{array}{l}6.887 * * * \\
(0.0871)\end{array}$ & $\begin{array}{l}6.854 * * * \\
(0.0875)\end{array}$ \\
\hline & $70+$ & $\begin{array}{l}10.28 * * * \\
(0.0889)\end{array}$ & $\begin{array}{l}7.151 * * * \\
(0.0871)\end{array}$ & $\begin{array}{l}7.130 * * * \\
(0.0872)\end{array}$ & $\begin{array}{l}7.084 * * * \\
(0.0876)\end{array}$ \\
\hline \multirow[t]{3}{*}{ Match vars } & Main doctor & & $\begin{array}{l}2.741^{* * * *} \\
(0.0151)\end{array}$ & $\begin{array}{l}2.391 * * * \\
(0.0156)\end{array}$ & $\begin{array}{l}2.395 * * * \\
(0.0157)\end{array}$ \\
\hline & Log-N visit & & $\begin{array}{l}1.138 * * * \\
(0.00805)\end{array}$ & $\begin{array}{l}0.966 * * * \\
(0.00828)\end{array}$ & $\begin{array}{l}0.978 * * * \\
(0.00833)\end{array}$ \\
\hline & Log-total visits & & $\begin{array}{l}6.813^{* * *} \\
(0.0130)\end{array}$ & $\begin{array}{l}7.116^{* * *} \\
(0.0134)\end{array}$ & $\begin{array}{l}7.096^{* * *} \\
(0.0135)\end{array}$ \\
\hline Doctor FE & & NO & NO & YES & YES \\
\hline Observations & & $15,908,358$ & $15,908,358$ & $15,908,358$ & $15,908,358$ \\
\hline R-squared & & 0.029 & 0.069 & 0.080 & 0.076 \\
\hline
\end{tabular}

Notes: Outcome variable is refill-based adherence rate, ranging between $0 \%$ and $100 \%$. Omitted categories include: Ace inhibitor for drug dummies; "Education N/A (not available, missing)" for education. Tertiary short term education includes theoretical educations of about 2 years of length. Tertiary medium term education covers bachelor degrees that are very occupation specific, e.g. teachers, nurses, physiotherapists etc.; First quartile for income; "Less than 30 years old” for age. Calendar year fixed effects included in every specification.

Increases in the price of a day's supply of the medication negatively affect adherence. The OLS results imply that a price increase of 1 DKK will reduce the medication possession ratio by about 0.9 percentage points. A more intuitive way to interpret this result is that an increase of one standard deviation in the price of a day's supply (1.35DKK) reduces medication compliance by $0.06-0.07$ standard deviations.

The OLS coefficient on the price variable could be biased due to a number of different factors. In column (4) we report the coefficient estimates from the second stage of an instrumental variable two-stage least squares regression ${ }^{16}$. The instrumental variables specification yields an estimate that is about $10 \%$ larger than the OLS estimate, consistent with the presence of attenuation bias in the OLS specifications. The estimated effect of cost on adherence is not negligible - it is of the same order of magnitude as the coefficient on foreign birth origin. Changing the out-of-pocket price encountered at the pharmacy from the $5^{\text {th }}$ to the $95^{\text {th }}$ percentile of the price distribution (from $0.02 \mathrm{DKK}$ to $2.7 \mathrm{DKK}$ per daily dose) would result in approximately 3 percent decrease in average adherence.

\footnotetext{
${ }^{16}$ The coefficient estimates from the first stage are reported in Table A3 in the Appendix. Due to the medication subsidy scheme, the relationship between the sticker price of a medication and the price paid by consumers could vary across drug groups and time periods. To control for some of that heterogeneity, in the first stage we include interactions between the government-mandated medication cost and drug dummies, as well as an indicator dummy for the first month of the subsidy year. We find that the Danish government subsidizes between $70 \%$ and $95 \%$ of the price of chronic medications.
} 
It is important to emphasize that the elasticity of adherence that can be constructed based on this estimate is not directly comparable to the price elasticities of demand reported in the related literature (Manning et al 1987; Chandra et al, 2010; Simonsen et al, 2013; Skipper, 2013). There are several important differences that preclude any direct comparisons. First, our adherence variable is truncated at $100 \%$. This excludes from the estimation variation arising from instances where patients responded to price shocks by acquiring drug inventories exceeding the number of days between subsequent refills. Second, we focus the adherence analysis on patients who purchase the medication now or later. Therefore the implicit outside option is not refraining from the purchase altogether, but postponing the purchase to a later date, thus stretching the current supply of medication over a longer period. Studies of price elasticity of demand for drugs consider the nopurchase option as the outside option. Third, it is well known that the price elasticity of demand decreases when stockpiling of goods is accounted for, especially when the comparable static (no stockpiling allowed) price elasticity estimate allows for substitution into the no-purchase option (Hendel and Nevo, 2006).

\section{Conclusion}

This paper presents the first analysis of the determinants of patient adherence with medication in a unified framework using individual physician- and patient-specific population panel data from Denmark. The Danish universal health insurance system allows us to analyze the contribution of various demographic and SES patient characteristics to differences in average adherence rates across population subgroups, net of financial constraints to obtaining care.

Similarly, we analyze the physician contribution to medication compliance in a system where doctors have no financial incentives to prescribe one course of therapy over another. Physicians can influence patients' health investment. However, there are significant heterogeneities in doctors' contributions to patient compliance both across physicians and across medication classes. Further, we find significant variation in adherence over time within a physician-patient pair. The patient's decision to follow the recommended therapy evolves with the doctor-patient relationship. Thus, a one-size-fits-all approach to improving average compliance by offering physician (or patient) incentives is likely to yield suboptimal results. 


\section{References}

Benner JS, Glynn RJ, Mogun H, Neumann PJ, Weinstein MC, Avorn J. (2002) ”Long-term persistence in use of statin therapy in elderly patients.” JAMA. July 24, 2002;288(4):455-461.

Chandra, A., J. Gruber, J. and R. McKnight (2010): "Patient Cost - Sharing and Hospitalization Offsets in the Elderly”, American Economic Review 100, 193-213.

Contoyannis, P., J. Hurley, P. Grootendorst, S. Jeon and R. Tablyn (2005): “Estimating the price elasticity of expenditure for prescription drugs in the presence of non-linear price schedules: an illustration from Quebec, Canada”, Health Economics 14, 909-923.

Cooper LA. (2009) ”A 41-year-old African American man with poorly controlled hypertension: review of patient and physician factors related to hypertension treatment adherence”. JAMA. March 25, 2009;301(12):1260-1272

DiMatteo, Robin (2004) "Variations in Patients' Adherence to Medical Recommendations: A Quantitative Review of 50 Years of Research” Medical Care, vol 42, issue 3

Gellad Walid F., Jerry Grenard, Elizabeth A. McGlynn (2009) ”A Review of Barriers to Medication Adherence: A Framework for Driving Policy Options” RAND Technical Report, 2009

Goldman, D. P., G. F. Joyce, J. J. Escarce, J. E. Pace, M. D. Solomon, M. Laouri, P. B. Landsman, and M. Teutsch (2004): "Pharmacy Benefits and the Use of Drugs by the Chronically Ill”, Journal of the American Medical Association 291, 2344-2350.

Hendel, Igal and Aviv Nevo (2006) "Measuring the Implications of Sales and Consumer Inventory Behavior” Econometrica, Vol. 74, no 6, 1637-1673

Jha, Ashish K., E. John Orav, and Arnold M. Epstein , “Low-Quality, High-Cost Hospitals, Mainly in South, Care for Sharply Higher Shares of Elderly Black, Hispanic, and Medicaid Patients,” Health Affairs 30, no. 10 (2011): 1904-11

Chien, Alyna T., Kristen Wroblewski, Cheryl Damberg, Thomas R. Williams, Dolores Yanagihara, Yelena Yakunina, and Lawrence P. Casalino, “Do Physician Organizations Located in Lower Socioeconomic Status Areas Score Lower on Pay-for-Performance Measures?”_Journal of General Internal Medicine 27, no. 5 (2012): 548-54.

Haynes RB, McDonald PM, Garg AX. (2000) "Helping patients follow prescribed treatment." JAMA. 2002; 288:2880-2883

Krueger, Kem, Bruce Berger and Bill Felkey (2005) Medication Adherence and Persistence: A Comprehensive Review” Advances in Therapy, Vol 22, No 4 August 2005

Landsman, P. B., W. Yu, X. F. Liu, S. M. Teutsch and M. L. Baerger (2005) "Impact of 3-Tier Pharmacy Benefit Design and Increased Consumer Cost-sharing on Drug Utilization.” The American Journal of Managed Care 11, 621-628. 
Manning, W. G., J. P. Newhouse, N. Duan, E. B. Keeler, A. Leibowitz, and M. S. Marquis (1987) "Health Insurance and the Demand for Medical Care: Evidence from a Randomized Experiment.” The American Economic Review 77, 251-277.

Moran, J. R. \& Simon, K. I. (2006) "Income and the Use of Prescription Drugs by the Elderly.” Journal of Human Resources, XLI, 2, 411-432.

Miura T, Kojima R, Mizutani M, Shiga Y, Takatsu F, Suzuki Y. Effect of digoxin noncompliance on hospitalization and mortality in patients with heart failure in long-term therapy: a prospective cohort study. Eur J Clin Pharmacol. 2001;57:77-83

Newhouse, J. (1993): Free for All: Lessons from the RAND Health Insurance Experiment. Cambridge, MA. Harvard University Press.

Rau, Jordan, “Medicare to Penalize 2,211 Hospitals for Excess Readmissions,” Kaiser Health News, August 13, 2012

Roter D. (1995) “Advancing the physician’s contribution to enhancing compliance.” $J$ Pharmacoepidemiol. 1995;3:37-48.

Simeonova, Emilia (2012) “Doctors, Patients and the Racial Mortality Gap”, Journal of Health Economics, 2013 July 12; 32(5)

Simeonova, Emilia (2012) “Marriage, Bereavement and Mortality” Journal of Health Economics, forthcoming

Simonsen, M., L. Skipper, and N. Skipper (2013): "Price Sensitivity of Demand for Prescription Drugs: Exploiting a Regression Kink Design”, Mimeo, Aarhus University.

Skipper, Niels (2013) “On the Demand for Prescription Drugs: Heterogeneity in Price Responses”, Health Economics 22 857-869.

Sleath B, Chewning B, Svarstad B, Roter D. (2000) "Patient expression of complaints and adherence problems with medications during chronic disease medical visits.” J Soc Admin Pharm. 2000;17: 71-80.

Tamblyn, R., R. Laprise, J. A. Hanley et al. (2001): Adverse Events Associated with Prescription Drug Cost-Sharing among Poor and Elderly Persons, Journal of the American Medical Association 285, 421-429.

Volpp, Kevin and Mark Pauly (2009) "United States: Orienting Pay-for-Performance to Patients” in Performance Incentives for Global Health: Potential and Pitfalls, The Brookings Institution Press, Baltimore, MD

World Health Organization. Adherence to Long-Term Therapies: Evidence for Action. Geneva, Switzerland; 2003. Available at: http://www.who.int/chp/knowledge/publications/adherence_full_report.pdf. 


\section{Appendix: tables and figures for online appendix only}

TABLE A1. ATC codes and pharmaceutical agents included in the main drug groups

\begin{tabular}{|c|c|c|}
\hline Drug group & ATC code & Active chemical agent \\
\hline \multirow[t]{9}{*}{ Ace inhibitors } & C09AA01 & captopril \\
\hline & C09AA02 & enalapril \\
\hline & C09AA03 & lisinopril \\
\hline & C09AA04 & perindopril \\
\hline & C09AA05 & ramipril \\
\hline & C09AA06 & quinapril \\
\hline & C09AA07 & benazepril \\
\hline & C09AA09 & fosinopril \\
\hline & C09AA10 & trandolapril \\
\hline \multirow[t]{5}{*}{ Beta blockers } & C07AA03 & pindolol \\
\hline & C07AA05 & propranolol \\
\hline & C07AA06 & timolol \\
\hline & C07AA07 & sotalol \\
\hline & C07AA16 & tertatolol \\
\hline \multirow[t]{8}{*}{ Oral anti-diabetics } & A10BA02 & metformin \\
\hline & A10BB01 & glibenclamide \\
\hline & A10BB03 & tolbutamide \\
\hline & A10BB07 & glipizide \\
\hline & A10BB09 & gliclazide \\
\hline & A10BB12 & glimepiride \\
\hline & A10BG03 & pioglitazone \\
\hline & A10BX02 & repaglinide \\
\hline \multirow[t]{6}{*}{ Statins } & C10AA01 & simvastatin \\
\hline & C10AA02 & lovastatin \\
\hline & C10AA03 & pravastatin \\
\hline & C10AA04 & fluvastatin \\
\hline & C10AA05 & atorvastatin \\
\hline & C10AA07 & rosuvastatin \\
\hline
\end{tabular}

Note: List of drugs that were prescribed within the four main groups.

Table A2. Summary statistics of drug prices (per day's supply) in DKK

\begin{tabular}{lll}
\hline Statistic & Out-of-pocket price & Shelf price \\
\hline $5 \%$ & 0.02 & 0.27 \\
$50 \%$ & 0.29 & 1.04 \\
$95 \%$ & 2.7 & 13.5 \\
Mean & 0.71 & 2.9 \\
Std. Dev. & 1.35 & 5.6 \\
N obs & $16,352,114$ & $16,352,114$ \\
\hline
\end{tabular}


TABLE A3 First stage of the drug price IV regression

\begin{tabular}{|c|c|}
\hline & OLS-FE \\
\hline BETA BLOCKER X FIRST MONTH & $\begin{array}{c}0.0548 * * * \\
(0.00497)\end{array}$ \\
\hline ANTI-DIABETIC X FIRST MONTH & $\begin{array}{l}0.117 * * * \\
(0.00294)\end{array}$ \\
\hline STATIN X FIRST MONTH & $\begin{array}{c}-0.241 * * * \\
(0.00212)\end{array}$ \\
\hline FIRST MONTH & $\begin{array}{l}0.469 * * * \\
(0.00158)\end{array}$ \\
\hline Auction price & $\begin{array}{l}0.0118 * * * \\
(6.71 \mathrm{e}-05)\end{array}$ \\
\hline BETA BLOCKER X Auction price & $\begin{array}{c}-0.00715 * * * \\
(0.000243)\end{array}$ \\
\hline ANTI-DIA BETIC X Auction price & $\begin{array}{l}-0.0126^{* * *} \\
(0.000134)\end{array}$ \\
\hline STATIN X Auction price & $\begin{array}{l}0.0953^{* * * *} \\
(0.000107)\end{array}$ \\
\hline FIRST MONTH X Auction price & $\begin{array}{c}0.103^{* * *} \\
(0.000282)\end{array}$ \\
\hline BETA BLOCKER X FIRST MONTH X Auction price & $\begin{array}{l}-0.0924 * * * \\
(0.000726)\end{array}$ \\
\hline ANTI-DIABETIC X FIRST MONTH X Auction price & $\begin{array}{l}-0.0895 * * * \\
(0.000469)\end{array}$ \\
\hline STATIN X FIRST MONTH X Auction price & $\begin{array}{l}0.0713^{* * *} \\
(0.000364)\end{array}$ \\
\hline BETA BLOCKER & $\begin{array}{c}-0.126^{* * *} \\
(0.00187)\end{array}$ \\
\hline ANTI-DIABETIC & $\begin{array}{c}-0.117 * * * \\
(0.00105)\end{array}$ \\
\hline STATIN & $\begin{array}{l}-0.236^{* * *} \\
(0.000798)\end{array}$ \\
\hline YEAR FE & YES \\
\hline PATIENT SOCIO-ECONOMIC CONTROLS & YES \\
\hline MATCH quality variables & YES \\
\hline DOCTOR FE & YES \\
\hline Constant & $\begin{array}{l}0.845^{* * *} \\
(0.00668)\end{array}$ \\
\hline Observations & $15,828,216$ \\
\hline R-squared & 0.250 \\
\hline
\end{tabular}

Notes: Outcome is out-of-pocket drug price, measured in DKK per day's supply. Reported variables are interactions of Drug, First month dummy, and Auction price. Also included, but not reported, are Year and Doctor fixed effects, as well as patient's socio-economic characteristics included in the adherence regressions. 